\title{
THE VEGF AND BMP-2 LEVELS IN PATIENTS WITH ANKYLOSING SPONDYLITIS AND THE RELATIONSHIP TO TREATMENT WITH TUMOUR NECROSIS FACTOR ALPHA INHIBITORS
}

\author{
Marian Tošovský, Petr Bradna ${ }^{1}$, Ctirad Andrýs ${ }^{2}$, Kateřina Andrýsováa ${ }^{3}$ Eva Čermáková ${ }^{4}$ Tomáš Soukup ${ }^{1}$
}

Charles University in Prague, Faculty of Medicine in Hradec Králové, and University Hospital Hradec Králové, Czech Republic $^{3}$ : 2nd Internal Gastroenterological Department ${ }^{1}$, Institute of Clinical Immunology and Allergology ${ }^{2}$, Institute of Medical Biophysics ${ }^{4}$

Summary: Introduction: Ankylosing spondylitis (AS) is an inflammatory rheumatic disease characterized by the development of osteoproductive changes in the spine which could possibly result in ankylosis. Treatment with tumour necrosis factor alpha (TNF $\alpha)$ inhibitors has proved to be an important step forward in the treatment of this disease, but for the time being it is not clear whether it favourably influences radiographic progression of the disease. Vascular endothelial growth factor most probably plays a role in the development of osteoproductive changes and recently its predictive influence on radiographic progression has been demonstrated. Bone morphogenic protein 2 (BMP-2) participates in the regulation of bone proliferation and its increased serum level has been demonstrated in patients with advanced AS and correlated with the degree of radiographic changes. Aim: The study aims to evaluate the VEGF and BMP-2 levels in patients with ankylosing spondylitis and how these levels relate to the concurrent treatment with TNFa inhibitors. Methods: Sera were evaluated from patients at the Rheumatologic Clinic of the Hradec Králové Faculty Hospital who fulfilled the modified New York Criteria for AS $(n=55)$. In these patients, the parameters of the activity of the disease (BASDAI = Bath Ankylosing Spondylitis Disease Activity Index, $\mathrm{CRP}=\mathrm{C}$-reactive protein) and the concurrent therapy (TNF $\alpha$ inhibitors, $\mathrm{n}=21$, vs. non-anti TNF $\alpha$, $\mathrm{n}=34$ ) were recorded. The levels of VEGF and BMP-2 were analyzed using the ELISA method. Results: In patients treated with TNF $\alpha$ inhibitors, a significantly lower VEGF level was found when compared to untreated patients (140.3 (109.4; $262.2)$ vs. $261(172.4 ; 396.6) \mathrm{pg} / \mathrm{ml} ; \mathrm{p}=0.02)$. No difference was found between BMP-2 levels in both groups (treated vs. untreated patients) $(254.8(2301 ; 267.3)$ vs. $261.1(248.6 ; 273.5) \mathrm{pg} / \mathrm{ml} ; \mathrm{p}=0.24)$. A correlation analysis did not reveal any relationship between VEG F and BMP-2 $(r=0.057 ; p=0.68)$. Serum levels of VEGF correlated with serum levels of CRP $(r=0.56 ; p=0.00001)$ and the BASDAI value $(r=0.33 ; p=0.015)$. Conclusion: Significantly lower VEGF levels were found in patients treated with TNF $\alpha$ inhibitors versus the untreated patients. These findings are in harmony with some hitherto published analyses and may give evidence of a favourable effect of TNF $\alpha$ inhibitors on radiographic progression. Neither influence on the BMP-2 level by treatment with TNF $\alpha$ inhibitors nor correlation with VEGF levels was demonstrated.

Key words: Ankylosing spondylitis; Axial spondyloarthritis; Vascular endothelial growth factor; Bone morphogenic factor 2; Radiographic progression

Ankylosing spondylitis (AS) is an inflammatory rheumatic disease which causes a number of difficulties in the musculoskeletal system. A typical manifestation in the axial skeleton is inflammatory back pain which is typically at its worse in the early morning and disappears or subsides after limbering up. The cause of the pain is supposed to be the inflammatory changes in the region of vertebral corners (bone swelling, bone marrow oedema), which magnetic resonance imaging (MRI) can reveal as an increased signal in the STIR (short tau inversion recovery) sequences (1). The relationship between the extent of changes in MR and the degree of infiltration of inflammatory cells was demonstrated by histopathological analysis in bioptic samples of sacro-iliac joints (2). Another feature is the development of osteoproductive changes in the longitudinal ligaments (syndesmophytes), which may result in complete spinal ankylosis.

In recent years there has been marked progress in the treatment of AS due to the appearance of the inhibitors of tumour-necrosis factor alpha $(\mathrm{TNF} \alpha)$. The treatment results in the apparent alleviation of pain and a decrease in inflammatory parameters in serum, and concurrently an effect on the disappearance of changes in MR (swelling of vertebral corners, bone marrow oedema) was demonstrated (1). Nevertheless, the opinions are not hitherto unequivocal whether the TNF $\alpha$ inhibitors influence radiographic progression (the development of new or deterioration of the existing radiographic changes in the spine typical of AS). 
The first two-year studies with TNF $\alpha$ inhibitors did not demonstrate a favourable effect on radiographic progression $(3,4,5)$. In addition, these data were supported by some experiments on animal models. For example, DBA/1 mice (mice with peripheral arthritis resulting in joint ankylosis) were used as a model of spondyloarthritis, in which the treatment with $\mathrm{TNF} \alpha$ inhibitors (etanercept) did not result in the prevention of joint ankylosis (6). It contributed to the opinion that inflammation and osteoproductive changes take place independently of each other.

Some more recent data suggest that osteoplastic changes in ankylosing spondylitis develop as independent reparative processes in the sites where the inflammatory changes ("early lesions") reached the limits of irreversible changes ("advanced lesions") (7). Early lesions were defined by an increased signal on STIR MR sequences; an advanced lesion is indicated by a decrease in the increased signal in STIR sequences from the apex of the vertebral corner and changes in T1 weighed scans in this localization (erosion, sclerotization, fat infiltration). By the action of various regulatory mechanisms there then develops proliferation of the bone, which then may take place independently of the presence or absence of inflammation. New syndesmophytes have been demonstrated to develop unequivocally more often in the sites of these "advanced lesions" (7).

It is assumed that vascular proliferation and vascular endothelial growth factor (VEGF) (due to its regulatory role) participate in the development of advanced lesions as well. Increased serum level of VEGF was demonstrated in patients with AS (8) and correlated with the activity of the disease (BASDAI, C-reactive protein) (9). A predictive effect of the serum level of VEGF on radiographic progression was also recently demonstrated (10). The present paper aims at comparing the serum levels of VEGF in patients with AS in relationship to ongoing treatment with $\mathrm{TNF} \alpha$ inhibitors. Another aim is to compare the BMP-2 (bone morphogenic protein) levels in patients treated and not treated with TNF $\alpha$ inhibitors and to examine the relationship between VEGF and BMP-2. BMP-2 participates in the regulation of bone proliferation and both its increased serum level in patients suffering from advanced AS and a positive correlation with the degree of radiographic changes were demonstrated (11)

\section{Material and Methods}

The analysis used the sera evaluated from patients at the Rheumatologic Clinic of the Hradec Králové Faculty Hospital who fulfilled the modified New York Criteria for AS $(n=55)(12)$. At the time of blood withdrawal, parameters of the activity of the disease (BASDAI = Bath Ankylosing Spondylitis Disease Activity Index (13), CRP = C-reactive protein) and the ongoing therapy (TNF $\alpha$ inhibitors, $n=21$, vs. non-anti TNF $\alpha, n=34$ ) were recorded. The VEGF level was analyzed by means of the ELISA (enzyme linked im- munosorbent assay) method with the use of a commercial Quantikine Human VEGF Immunoassay kit, R\&D Systems, Inc., USA. The BMP-2 level was also measured by means of the ELISA method using a BMP2 Human ELISA Kit, Abcam (UK). The levels of C-reactive protein (CRP) were assayed immunoturbidimetrically on a Modular analyzer (Roche, Switzerland) using the diagnostic agents of the same firm.

The values of the parameters were presented by the median and 95\% confidence interval for the median. A box diagram was employed for graphic presentation. Differences between the groups were evaluated using the double-selection t-test, or nonparametric Mann-Whitney, Kolmogorov-Smirnov tests. Spearman coefficient of rank correlation was employed to evaluate the relations of the parameters. The selected level of significance was $\alpha=0.05$.

Informed consent was obtained. The study was carried out according to the Declaration of Helsinki. The procedures were approved by the local ethics committee.

\section{Results}

The principal characteristics of the cohort are summarized in Table 1. The median age of patients treated with TNF inhibitors $(\mathrm{n}=21)$ vs. those untreated $(\mathrm{n}=34)$ was 42 $(37 ; 46)$ vs. $47.5(38 ; 57)$ years and no statistically significant difference between the groups was found $(\mathrm{p}=0.06)$. The representation of males in both groups was $85.7 \%(18 / 21)$ and $82.4 \%(28 / 34)$, respectively. The length of duration of disease was similar in both groups (median 13 and 17 years, respectively, $\mathrm{p}=0.08)$. No difference was found between both groups in the values of serum level of CRP (3.2 (0.6; $6.1)$ vs. $4.95(2.7 ; 6.8) \mathrm{mg} / \mathrm{l} ; \mathrm{p}=0.24)$. The BASDAI value was significantly lower in patients treated with TNF $\alpha$ inhibitors $(20.0(10.6 ; 27.0)$ vs. $35.8(24.0 ; 43.6) ; \mathrm{p}=0.00047)$. The median length of the treatment with TNF $\alpha$ inhibitors was $40(9 ; 59)$ months. The representation of the individual preparations is shown in Table 2.

Tab. 1: Characteristics of patients cohorts $(\mathrm{CRP}=\mathrm{C}$-reactive protein, BASDAI = Bath ankylosing spondylitis disease activity index).

\begin{tabular}{|l|l|l|l|}
\hline & \multicolumn{1}{|c|}{ TNF $\boldsymbol{\alpha}$} & non TNF $\boldsymbol{~}$ & \\
\hline $\begin{array}{l}\text { age, median } \\
\text { (mean) }\end{array}$ & $42(42.8)$ & $47.5(49,4)$ & $p=0.06$ \\
\hline $\begin{array}{l}\text { \% incidence of } \\
\text { men }\end{array}$ & $85.7(18 / 21)$ & $82.4(28 / 34)$ & \\
\hline $\begin{array}{l}\text { lengh of duration } \\
\text { of the disease } \\
\text { (years) }\end{array}$ & $13(15.6)$ & $17(22.0)$ & $p=0.08$ \\
\hline $\begin{array}{l}\text { CRP mg/l, } \\
\text { median (mean) }\end{array}$ & $3.2(8.1)$ & $4.95(8.5)$ & $p=0.24$ \\
\hline $\begin{array}{l}\text { BASDAI, median } \\
\text { (mean) }\end{array}$ & $20.0(19.8)$ & $35.8(37.2)$ & $p=0.00047$ \\
\hline
\end{tabular}


Tab. 2: Representation of the individual TNF $\alpha$ inhibitors.

\begin{tabular}{|l|r|}
\hline Infiximab (5 mg/kg à 6 weeks) & 2 \\
\hline Adalimumab (40 mg à 2 weeks) & 14 \\
\hline Etanercept (50 mg à 1 week) & 3 \\
\hline Golimumab (50 mg à 1 month) & 2 \\
\hline
\end{tabular}

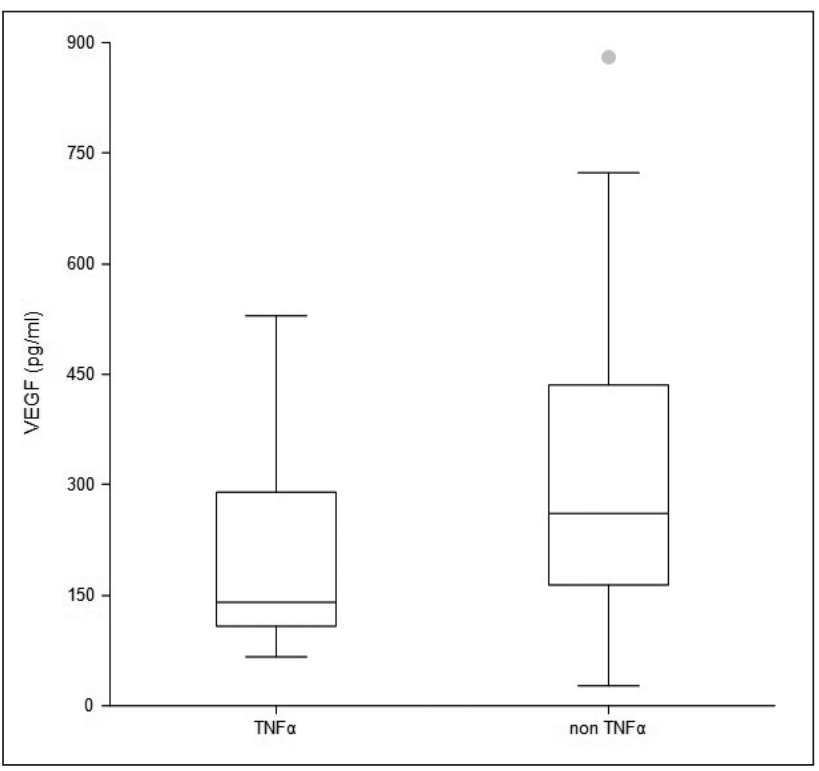

Fig. 1: Box plot graph, levels of VEGF $(\mathrm{pg} / \mathrm{ml})$ in patients treated and not treated with TNF $\alpha$ inhibitors (VEGF = Vascular Endothelial Growth Factor, TNF = Tumour Necrosis Factor).

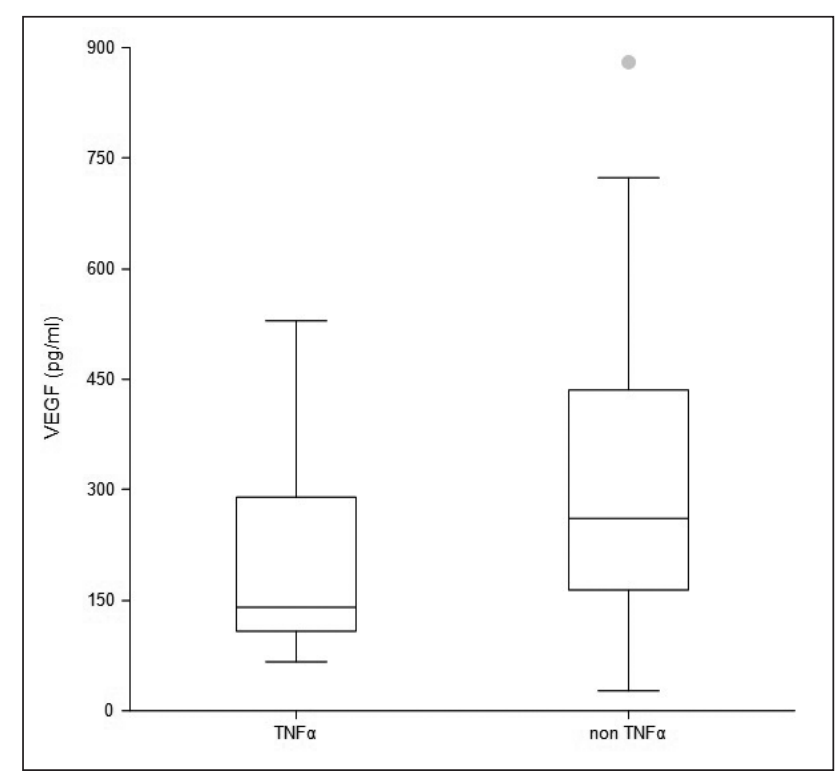

Fig. 3: Relationship between VEGF (pg/ml) and CRP (mg/l) $($ VEGF $=$ Vascular Endothelial Growth Factor, CRP $=$ C-reactive protein), correlation analysis, $(r=0.56 ; p=0.00001)$.
In patients treated with TNF $\alpha$ inhibitors, a significantly lower VEGF level was found in comparison with the untreated patients $(140.3(109.4 ; 262.2)$ vs. $261(172.4 ; 396.6)$ $\mathrm{pg} / \mathrm{ml} ; \mathrm{p}=0.02$ ) (Figure 1).

No difference was found between the BMP-2 levels in both groups (treated vs. untreated patients) (254.8 (230.1; $267.3)$ vs. $261.1(248.6 ; 273.5) \mathrm{pg} / \mathrm{ml} ; \mathrm{p}=0.24)$ (Figure 2).

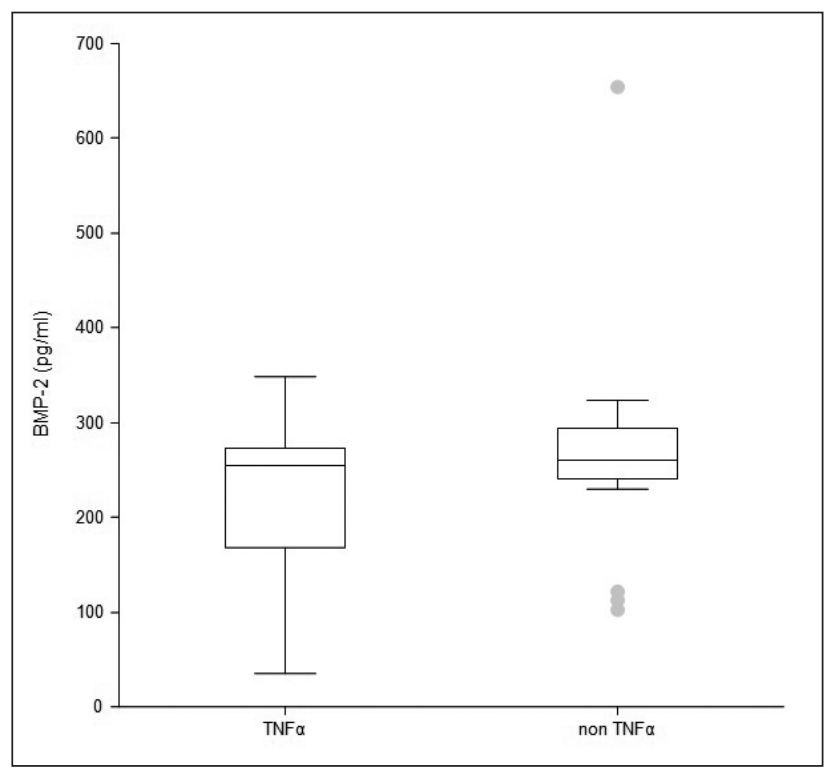

Fig. 2: Box plot graph, levels of BMP-2 (pg/ml) in patients treated and not treated with TNF $\alpha$ inhibitors $(\mathrm{BNP}=$ Bone Morphogenic Protein, $\mathrm{TNF}=$ Tumour Necrosis Factor).



Fig. 4: Relationship VEGF (pg/ml) and BASDAI (VEGF = Vascular Endothelial Growth Factor, BASDAI = Bath ankylosing spondylitis disease activity index), correlation analysis, $(r=0.33 ; p=0.015)$. 


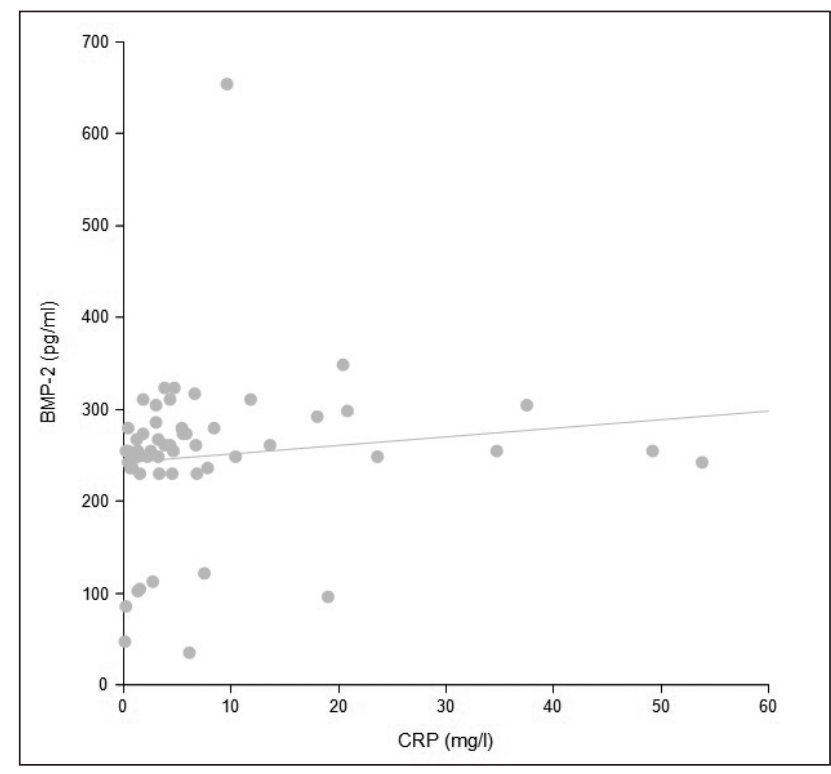

Fig. 5: Relationship between BMP-2 (pg/ml) and CRP (mg/l) $(\mathrm{BMP}=$ Bone Morphogenic Protein, $\mathrm{CRP}=\mathrm{C}$-reactive protein $)$, correlation analysis, $(\mathrm{r}=0.28 ; \mathrm{p}=0.036)$.

A correlation analysis did not reveal a relationship between VEGF and BMP-2 ( $\mathrm{r}=0.057 ; \mathrm{p}=0.68)$.

Serum levels of VEGF correlated with serum levels of $\mathrm{CRP}(\mathrm{r}=0.56 ; \mathrm{p}=0.00001)$ and the BASDAI value $(\mathrm{r}=0.33$; $\mathrm{p}=0.015)$ (Figure 3, resp. 4). A mild correlation between BMP-2 and CRP $(r=0.28 ; \mathrm{p}=0.036)$ and even no correlation between BMP-2 and BASDAI $(r=0.056, p=0.68)$ were found (Figures 5 and 6).

\section{Discussion}

It is difficult to know whether TNF $\alpha$ inhibitors influence radiographic progression in patients suffering from AS. This issue is being intensively investigated but important limitations exist. One of them is the fact that ossification in the region of longitudinal ligaments is a very slow process, often lasting many years. Due to ethical reasons therefore there cannot be placebo-controlled, randomized studies with $\mathrm{TNF} \alpha$ inhibitors, although such studies would demonstrate the possible effect on the radiographic progression. In such patients one key problem is how to determine the radiographic progression itself. At present, determining a change in the mSASSS spinal score (modified Stokes ankylosing spondylitis spinal score) is considered valid. This score evaluates changes in lateral $\mathrm{x}$-rays of the lumbar and cervical spine by means of a scoring system (14).

One of the possibilities of how to evaluate the effect of the treatment on radiographic progression is to determine the predictors of radiographic progression and to monitor whether these markers are influenced by therapy. Determining the predictors of radiographic progression is

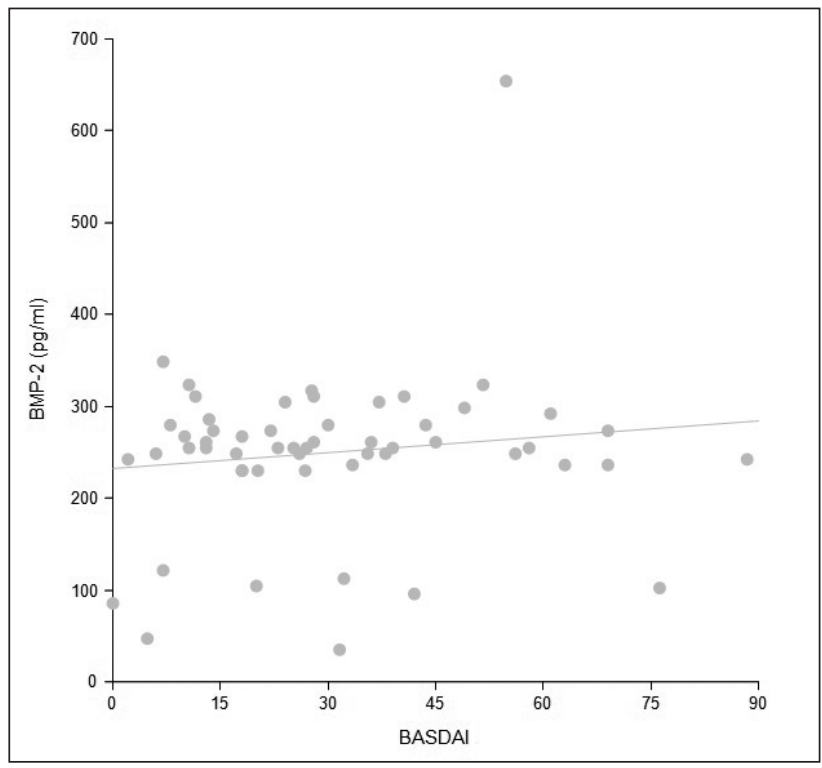

Fig. 6: Relationship BMP-2 (pg/ml) and BASDAI $(\mathrm{BMP}=$ Bone Morphogenic Protein, BASDAI = Bath ankylosing spondylitis disease activity index $)$, correlation analysis, $(\mathrm{r}=0.056 ; \mathrm{p}=0.68)$.

a considerably complex process and requires monitoring the spinal score at sufficiently long-term time intervals. The first data in this respect already exist. For example, a predictive effect on radiographic progression in CRP and ESR (erythrocytes sedimentation rate) was demonstrated in this way (15). Another predictor of radiographic progression is then the extent of the already present radiographic changes themselves at the beginning of monitoring (15).

VEGF is a signal protein which plays a role in the regulation of angioneogenesis and has an irreplaceable role in inflammatory processes generally. In patients suffering from AS (8) or spondyloarthritis $(9,16)$, increased VEGF levels in comparison with control groups of healthy subjects was demonstrated and these levels correlated with clinical (BASDAI) (9) and laboratory $(8,9)$ markers of activity. Also, in our group of patients the VEGF levels correlated with the BASDAI and CRP levels.

The latest data have also demonstrated a predictive effect of VEGF on radiographic progression in patients with spondyloarthritis. Poddubnyy et al. (10) carried out an analysis of 172 patients with axial spondyloarthritis in which they evaluated whether VEGF predicted radiographic progression during a two year period of monitoring. They have demonstrated that patients with greater radiographic progression ( $\geq 2 \mathrm{mSASSS}$ units) possessed significantly higher VEGF levels versus the group of patients without radiographic progression. The same occurred when they evaluated the development of new syndesmophytes. Similar data demonstrating the predictive effect of the VEGF level on radiographic progression were also published earlier in a study involving a group of 52 patients with a definite diagnosis of AS (17). 
The present authors' evaluation has demonstrated significantly lower serum VEGF levels in patients treated with $\mathrm{TNF} \alpha$ inhibitors versus the untreated patients. These data are in accordance with the data of other authors in whose studies the administration of TNF $\alpha$ inhibitors resulted in a decrease in the VEGF level $(16,18,19,20,21)$. For the time being it is not clear whether TNF $\alpha$ inhibitors influence radiographic progression in patients with AS. Nevertheless, as shown by our data, in patients who underwent the treatment the VEGF level, an important predictor of radiographic progression, was significantly lower.

Besides regulation of angioinvasion and pathogenesis of inflammatory changes, VEGF plays simultaneously a key role in the process of enchondral ossification $(22,23)$. It is not therefore quite clear in which part of the complex process of ossification in patients with AS it exerts its principal influence, whether it is in the development of advanced lesions, or as late as the process of enchondral ossification itself. The serum level of VEGF then may include both of these components and the predictive effect of VEGF on radiographic progression may be a manifestation of the first or the second, or the sum total of both phenomena. In our patients, the VEGF level did not correlate with BMP-2, which participates in the regulation of bone proliferation, and in patients with AS its level correlated with the spinal score (11). However, the predictive influence on radiographic progression has not been determined in this protein.

The question arises as to why, in the two-year studies with TNF $\alpha$ inhibitors, no impact on radiographic progression occurs. In this connection the "TNF brake theory" (TNF brake) is mentioned, which states that TNF $\alpha$ acts by way of Dickkopf-1 as the inhibitor of osteoproduction; and suppression of inflammation thus, on the other hand, may start the osteoproductive changes. However, another explanation may be the theory of early and advanced lesions. As mentioned in the introduction, TNF $\alpha$ inhibitors favourably influence the inflammatory changes in the region of vertebral corners. In the case of an early lesion there occurs disappearance ad integrum; but it is the lesion alone which, without treatment, would develop in a syndesmophyte after a much longer period than two years. In the case of an advanced lesion osteoproductive changes probably occur independently of the activity of inflammation. On the other hand, through the mechanism of the TNF brake, osteoproductive processes may be accelerated by treatment. It would thus mean that in this respect the benefit for the patient would be primarily the early onset of therapy, which is in accordance with the latest results. Baraliakos et al. published eight-year data of patients with AS, comparing the development of the spinal score over the course of eight years in patients treated with inflixmab in comparison with an untreated cohort. At the beginning, both groups did not significantly differ in the parameter of the spinal score. Patients treated with TNF $\alpha$ inhibitors showed, after eight years, a significantly lower change in the spinal score than the untreated patients, and the change in the spinal score in the first four years was similar; on the other hand, it was more expressed between the fourth and eighth years of monitoring. The number of syndesmophytes after eight years was significantly lower in treated versus untreated patients, though the numbers of syndesmophytes at the beginning of monitoring were similar (24). Another analysis performed by Haroon et al. found that patients with a later onset of therapy ( $>10$ years) showed a greater risk of radiographic progression than patients with an early onset of treatment. Radiographic progression was then lower in the patients treated with TNF $\alpha$ inhibitors, if the time period between the compared pictures was more than 3.9 years $(25)$.

When discussing the possible favourable influence of treatment with TNF $\alpha$ inhibitors on radiographic progression, it is relevant to mention the recent evidence of the positive effect of non-steroidal anti-inflammatory drugs (NSA): the conventional treatment of patients with AS. There is one randomised study and a few other studies showing evidence that taking NSA continuously or in higher doses favourable affects the spinal radiographic progression in these patients $(26,27,28,29)$.

\section{Conclusion}

VEGF most probably plays a role in the pathogenesis of the development of osteoproductive changes in patients suffering from AS as it has been recently discovered to be a predictive biomarker of radiographic progression in these patients. The present authors' analysis found that in patients treated with TNF $\alpha$ inhibitors there was a significantly lower level of VEGF than in untreated patients, which was in accordance with some hitherto published analyses. This finding contributes to other evidence of the positive effect of TNF $\alpha$ inhibitors on radiographic progression in patients suffering from AS. The amount of evidence has been on the increase recently. The present study did not demonstrate any effect on the BMP-2 level during treatment with TNF $\alpha$ inhibitors or a correlation with VEGF levels.

\section{References}

1. Braun J, Baraliakos X, Golder W, et al. Magnetic resonance imaging examinations of the spine in patients with ankylosing spondylitis, before and after successful therapy with infliximab: evaluation of a new scoring system. Arhritis Rheum 2003; 48: 2236-36.

2. Bollow M. Fischer T, Reisshauer H, et al. Quantitative analyses of sacroiliac biopsies in spondylarthropathies: $\mathrm{T}$ cell and macrophages predominate in early and active sacroileitis - cellularity correlates with degree of enhancement detected by magnetic resonance imaging. Ann Rheum Dis 2000; 59: 135-40.

3. van der Heijde D, Landewé R, Einstein S, et al. Radiographic progression of ankylosing spondylitis after up two years of treatment with etanercept. Arthritis Rheum 2008; 58: 1324-31.

4. van der Heijde D, Landewé $R$, Baraliakos $X$, Houben $H$, van Tubergen A, et al. Radiographic findings following two years of infliximab therapy in patients with ankylosing spondylitis. Arthritis Rheum 2008; 58: 3063-70.

5. van der Heijde D, Salonen D, Weissman BN, Landewé R, Maksymowych WP et al. Assessment of radiographic progression in the spines of patients with ankylosing spondylitis treated with adalimumab for up to 2 years. Arthritis Res Ther 2009; 11: R127.

6. Lories RJU, Derese I, deBari C, Luyten FP. Evidence for uncoupling of inflammation and joint remodeling in a mouse model of spondylarthritis. Arthritis Rheum 2007; 56: 489-497. 
7. Maksymowych WP, Morency N, Conner-Spady B, Lambert RG. Suppression of inflammation and effects on new bone formation in ankylosing spondylitis: evidence for a window of opportunity in disease modification. AnnRheum Dis, 2013; 72: 23-28.

8. Goldberger C, Dulak J, Duftner C, et al. Vascular endothelial growth factor (VEGF) in ankylosing spondylitis - a pilot study. Wien Med Wochenschr 2002; 152: $223-5$.

9. Drouart M, Saas P, Billot M, et al. High serum vascular endothelial growth factor correlates with disease activity of spondylarthropathies. Clin Exp Immunol 2003; 132: 158-62.

10. Poddubnyy D, Conrad K, Haibel H, et al. Elevated serum level of the vascular endothelial growth factor predicts radiographic spinal progression in patients with axial spondylarthritis. Ann Rheum Dis 2013 Aug 16. doi: 10.1136/annrheumdis -2013-203824. [Epub ahead of print]

11. Chen HA, Chen CH, Lin YJ, et al. Association of bone morphogenetic protein with spinal vision in ankylosing spondylitis. J Rheumatol 2010; 37(10): 2126-32.

12. Van der Linden S, Valkenburg HA, Cats A. Evaluation of diagnostic criteria for ankylosing spondylitis: a proposal for modification of the New York criteria. Arthritis Rheum 1984; $27: 361-8$

13. Calin A, Nakache JP, Gueguen A, Zeidler H, Mielants H, Dougados M. Defining disease activity in ankylosing spondylitis: is a combination of variables (Bath Ankylosing Spondylitis Disease Activity Index) an appropriate instrument? Rheumatology 1999; 38: 878-82.

14. Creemers MC, Franssen MJ, van't Hof MA, Gribnau FW, van de Putte LB, van Riel PL. Assessment of outcome in ankylosing spondylitis: an extended radiographic scoring system. Ann Rheum Dis 2005; 64: 127-9.

15. Poddubnyy D, Haibel H, Listing J, et al. Baseline radiographic damage, elevated acute-phase reactant levels, and cigarette smoking status predict spinal radiographic progression in early axial spondylarthritis. Arthritis Rheum 2012; 64: $1388-98$.

16. Pedersen SJ, Hetland ML, Sorensen IJ, et al. Circulating levels of interleukin-6, vascular endothelial growth factor, YKL-40, matrix metalloproteinase-3, and total aggrecan in spondyloarthritis patients during 3 years of treatment with TNFalpha inhibitors. Clin Rheumatol 2010; 29: 1301-9.

17. Poddubnyy D, Conrad K, Syrbe U, et al. Elevated serum level of the vascular endothelial growth factor is highly predictive for new syndesmophytes formation in patients with ankylosing spondylitis. Arthritis Rheum 2012; 64 (Suppl): S1054

18. Visvanathan S, Wagner C, Marini JC, et al. Inflammatory biomarkers, disease activity and spinal disease measures in patients with ankylosing spondylitis after treatment with infliximab. Ann Rheum Dis 2008; 67: 511-17.
19. Visvanathan S, van der Heijde D, Deodhar A, et al. Effects of infliximab on markers of inflammation and bone turnover and associations with bone mineral density in patients with ankylosing spondylitis. Ann Rheum Dis 2009; 68: 175-82.

20. Appel H, Janssen L, Listing J, et al. Serum levels of biomarkers of bone and cartilage destruction and new bone formation in different cohorts of patients with axial spondyloarthritis with and without tumour necrosis factor-alpha blocker treatment. Arthritis Res Ther 2008; 10: R125.

21. Pedersen SJ, Sorensen IJ, Garnero P, et al. ASDAS, BASDAI and different treatment responses and their relation to biomarkers of inflammation, cartilage and bone turnover in patients with axial spondyloarthritis treated with TNFalpha inhibitors. Ann Rheum Dis 2011; 70: 1375-81.

22. Patil AS, Sable RB, Kothari RM. Occurrence, biochemical profile of vascular endothelial growth factor (VEGF) isoforms and their functions in endochondra ossification. J Cell Physiol 2012; 227: 1298-308.

23. Gerber HP, Vu TH, Ryan AM, et al. VEGF couples hypertrophic cartilage remodeling, ossification and angiogenesis during endochondral bone formation. Nat Med 1999; 5: 623-8.

24. Baraliakos X, Haibel H, Listing J, Sieper J, Braun J. Continous long-term anti-TNF therapy does not lead to an increase in the rate of new bone formation over 8 years in patients with ankylosing spondylitis. Ann Rheum Dis 2014 Apr 1; 73(4): 710-5. doi: 10.1136/annrheumdis-2012-202698. Epub 2013 Mar 16.

25. Haroon N, Inman RD, Learch TJ, et al. The impact of tumour necrosis factor alph inhibitors on radiographic progression in ankylosing spondylitis. Arthritis Rheum 2013; 65(10): 2645-54

26. Wanders A, van der Heijde D, Landewé R, et al. Nonsteroidal antiinflammatory drugs reduce radiographic progression in patients with ankylosing spondylitis: a randomized clinical trial. Arthritis Rheum 2005; 52(6): 1756-65.

27. Haroon N, Kim TH, Inman RD. NSAIDs and radiographic progression in ankylosing spondylitis Bagging big game with small arms? Ann Rheum Dis 2012; 71(10): 1593-5.

28. Kroon F, Landewé R, Dougados M, van der Heijde D. Continuos NSAID use reverts the effects of inflammation on radiographic progression in patients with ankylosing spondylitis. Ann Rheum Dis 2012; 71(10): 1623-9.

29. Poddubnyy D, Rudwaleit M, Haibel H, et al. Effect of non-steroidal anti-inflammatory drugs on radiographic spinal progression in patients with axial spondyloarthritis: results from the German Spondyloarthritis Inception Cohort. Ann Rheum Dis 2012; 71(10): 1616-22.

Supported by the Ministry of Health of the Czech Republic - RVO (FNHK, 00179906).

Received: 09/05/2014

Accepted in revised form: 23/06/2014

\section{Corresponding author:}

MUDr. Marian Tošovský, 2nd Internal Gastroenterological Department, University Hospital, Sokolská 581, 500 05, Hradec Králové, Czech Republic; email: tosmar@post.cz 